\title{
Anabases
}

ANABASES Traditions et réceptions de l'Antiquité

$24 \mid 2016$

Varia

\section{Anthony Corbeill, Sexing the World. Grammatical Gender and Biological Sex in Ancient Rome}

Sarah Rey

\section{(2) OpenEdition}

Journals

Édition électronique

URL : http://journals.openedition.org/anabases/5745

DOI : 10.4000/anabases. 5745

ISSN : 2256-9421

Éditeur

E.R.A.S.M.E.

Édition imprimée

Date de publication : 10 novembre 2016

Pagination : 338-339

ISSN : 1774-4296

\section{Référence électronique}

Sarah Rey, " Anthony Corbeill, Sexing the World. Grammatical Gender and Biological Sex in Ancient Rome

», Anabases [En ligne], 24 | 2016, mis en ligne le 15 novembre 2016, consulté le 23 septembre 2020.

URL : http://journals.openedition.org/anabases/5745; DOI : https://doi.org/10.4000/anabases.5745

Ce document a été généré automatiquement le 23 septembre 2020.

(c) Anabases 


\title{
Anthony Corbeill, Sexing the World. Grammatical Gender and Biological Sex in Ancient Rome
}

\author{
Sarah Rey
}

\section{RÉFÉRENCE}

Anthony Corbeill, Sexing the World. Grammatical Gender and Biological Sex in Ancient Rome, Princeton and Oxford, Princeton University Press, 2015, 216 p.

45 dollars / isbn 978-0-691-16322-2

1 L'ouvrage d'Anthony Corbeill invite à une belle réflexion sur le genre des mots et sur le partage du monde qu'il crée. Dans ce domaine, l'auteur cherche à tester la validité de la thèse des deux anthropologues Edward Sapir et Benjamin Lee Whorf, qui ont voulu montrer que le langage des individus conditionnait leurs perceptions. Sur ce point, les Romains - de Térence à Servius, de Catulle à Augustin - apportent à l'auteur de riches confirmations. A. Corbeill soumet à son lecteur des textes étonnants, qui révèlent une pensée «sexuée» des choses, animées ou inanimées, dans laquelle la priorité est donnée au masculin, meilleur par principe : meliori sexui..., id est masculino (Serv., Aen., 2, 457). Une argumentation en cinq chapitres est proposée: 1. Roman Scholars on Grammatical Gender and Biological Sex. 2. Roman Poets on Grammatical Gender. 3. Poetic Play with Sex and Gender. 4. Androgynous Gods in Archaic Rome. 5. The Prodigious Hermaphrodite.

2 Cette enquête vise à comprendre l'essentialisation du genre grammatical, ou bien ce que l'auteur appelle "l'hétérosexualisation du monde». Les grammairiens latins s'interrogent sans fin sur le sexus des mots, dont on redoute les confusions ou les variations, d'où les traités De indiscretis generibus de Valerius Probus et de Nonius Marcellus. Chaque genre doit rester à sa place, dans sa sphère d'action appropriée. Ainsi, Servius (Aen., 8, 571) loue-t-il Virgile d'avoir employé le verbe uiduare pour 
décrire les méfaits de Mézence : le roi étrusque a dépeuplé la cité, l'a rendue "veuve de » nombreux citoyens ; or, note le scholiaste, le terme Vrbs est féminin, bien propre par conséquent - à incarner le deuil, à l'imitation des Romaines qui jouent un grand rôle dans les cérémonies funèbres.

Les poètes, quant à eux, prennent des libertés dans l'usage des genres qui désarment leurs exégètes antiques. Le jeu sur les mots et leurs sexes permet de lire en creux l'histoire de la soumission volontaire des écrivains latins à leurs prédécesseurs grecs. $\mathrm{Si}$ funis devient féminin chez Lucrèce, c'est en souvenir de la seirê grecque. Si arcus est de même féminisé, c'est pour rendre hommage à Iris, son modèle hellénique. Cette malléabilité du latin, qui autorise le transfert sexué d'un mot aussi important que dies dans le cours du $\mathrm{I}^{\mathrm{er}}$ siècle av. J.-C., fait place à une progressive rigidification. A. Corbeill montre au passage que la manipulation des genres n'est pas toujours là où on le croit : les Métamorphoses d'Ovide n'en abusent curieusement pas.

4 Avec le passage au christianisme, la grammaire devient un objet de polémique. L'auteur évoque Arnobe, accusant les païens d'avoir besoin d'attribuer un sexe à leurs divinités. Augustin revient à la charge lorsqu'il décrit la cohorte des dieux et déesses du paganisme aux compétences très circonscrites et très marquées par leurs sexes respectifs, dont l'anthropomorphisme trahit la fausseté. Le dieu des chrétiens, lui, outrepasse l'alternative masculin/féminin. L'ouvrage se termine par un chapitre sur les hermaphrodites, ces créatures qui provoquent la terreur des Romains et dont l'existence est vue comme un prodige qui appelle une expiation collective. A. Corbeill explique comment le vocabulaire latin tarde à se stabiliser autour des termes androgynus et hermaphroditus, avant de faire un sort à certaines interprétations modernes du phénomène qui forcent les sources antiques (L. Brisson). Dans cette partie du livre, comme il l'a fait ponctuellement ailleurs, l'auteur ouvre une fenêtre anthropologique sur la polyvalence du « troisième sexe » d'une culture à l'autre, et cite notamment les Navajos pour qui ces naissances hors norme ne sont pas inquiétantes.

Étranger au dogmatisme de certaines gender studies, ce Sexing the World intéressera les historiens autant que les latinistes. Il est agréable à lire, les considérations grammaticales n'y sont jamais abstruses. Il convainc de la présence chez les Anciens d'une croyance en la « juste » division des sexes. L'argumentation d'A. Corbeill prend la forme d'un libre cheminement, qui ne s'interdit pas, pour le plaisir et l'instruction de son lecteur, des détours par Tristram Shandy, Jules et Jim ou la morphologie des langues modernes. L'histoire des études n'est pas négligée : les théories indo-européennes de Jacob Grimm sur le genre primitif des mots ou l'interprétation du sexe des dieux étrusques par Massimo Pallottino sont judicieusement rappelées. La mention incidente (p. 75) d'une monnaie grecque figurant une allégorie du Sénat romain et dont la légende maladroite désigne «la » sénat (SACRA SINATUS), contamination probable de la boulè, donne à présent l'envie de lire le pendant archéologique d'une telle enquête. 


\section{AUTEURS}

SARAH REY

Université de Valenciennes

sarah.rey@univ-valenciennes.fr 